\title{
Avaliação da atividade antibacteriana dos extratos de Avicennia schaueriana Stapf \& Leechm. ex Moldenke, Verbenaceae
}

\author{
Sidnei C. dos Santos, ${ }^{* 1,2}$ Fábio S. Ferreira, ${ }^{1,2}$ Alcinéia O. Damião, ${ }^{1}$ Aldinéia O. Damião, ${ }^{1}$ \\ Tânia F. Barros, ${ }^{2}$ Juan C. Rossi-Alva, ${ }^{1}$ Luzimar Gonzaga Fernandez ${ }^{1,3}$
}

\author{
${ }^{1}$ Laboratório de Estudos em Meio Ambiente, Superintendência de Pesquisa e Pós-graduação, \\ Universidade Católica do Salvador, Av. Professor Pinto de Aguiar, 2589, Pituaçu, 41740-090 Salvador-BA, Brasil \\ ${ }^{2}$ Laboratório de Pesquisa em Microbiologia Clínica, Faculdade de Farmácia, Universidade Federal da Bahia, \\ Rua Barão de Geremoabo s/n, ,Campus Universitário, Ondina, 40170-290 Salvador-BA, Brasil \\ ${ }^{3}$ Laboratório de Bioquímica, Biotecnologia e Bioenergia, Departamento de Biofunção, Instituto de Ciências da \\ Saúde, Universidade Federal da Bahia, Av. Reitor Miguel Calmon s/n, Vale do Canela, 40160-000 Salvador-BA, \\ Brasil.
}

\begin{abstract}
RESUMO: A flora tem sido uma fonte valiosa de constituintes bioativos para manutenção da saúde humana. Tal fato tem reforçado a crescente investigação do potencial terapêutico das plantas medicinais. Neste contexto, o presente trabalho teve como objetivo avaliar o potencial antibacteriano dos extratos hidro-alcoólicos da casca, folha, e raiz de Avicennia schaueriana Stapf \& Leechm. ex Moldenke, Verbenaceae. As partes vegetais foram coletadas no povoado pesqueiro de Siribinha, Bahia e os extratos vegetais foram preparados pelo método de maceração. Todos os testes de sensibilidade dos extratos vegetais foram avaliados por meio de testes não-paramétricos. $\mathrm{O}$ extrato da raiz de $A$. schaueriana apresentou uma atividade inibitória do crescimento superior aos extratos da folha e casca, com halos de inibição que variaram entre 7 a $18 \mathrm{~mm}$ de acordo com as concentrações e as cepas bacterianas testadas. Já a concentração inibitória mínima dos extratos hidro-alcoólicos de $A$. schaueriana apresentaram uma média de valores entre 0,62 a $10,00 \mathrm{mg} / \mathrm{mL}$ para as bactérias analisadas. Os resultados estatísticos confirmaram a diferença de sensibilidade dos microrganismos estudados frente aos extratos de $A$. schaueriana.
\end{abstract}

Unitermos: Avicennia schaueriana, Verbenaceae, atividade antibacteriana, extrato vegetal.

\begin{abstract}
Evaluation of the antibacterial activity of extracts of Avicennia schaueriana (Stapf \& Leechm. ex Moldenke, Verbenaceae". Natural products have been a valuable bioactives constituent source for maintenance of the health human being. Such fact has strengthened the increasing inquiry of the therapeutical potential of medicinal plants. This work had as objective evaluate the antibacterial potential from leaf, root and bark hydro-alcoholics extracts of Avicennia schaueriana Stapf \& Leechm. ex Moldenke, Verbenaceae. The plant parts had been collected in the fishing town of Siribinha, Bahia and the plant extracts had been prepared by the method of maceration. All the tests of sensitivity of plant extracts had been evaluated by means of notparametric tests. The results of the test of diffusion in disk showed that the extract of the root of the A. schaueriana had been higher to extracts of the leaf and bark, with inhibition rings from growth varying of 7 to $18 \mathrm{~mm}$; in accordance with the tested concentrations. Already the minimum inhibitory concentration of hydro-alcoholic extracts of $A$. schaueriana had presented an average of values between 0,62 to $10,00 \mathrm{mg} / \mathrm{mL}$ for the analyzed bacteria. The statistical results had confirmed the difference of sensitivity of the studied microorganisms front to extracts of the A. schaueriana.
\end{abstract}

Keywords: Avicennia schaueriana, Verbenaceae, antibacterial activity, plant extract.

\section{INTRODUÇÃO}

$\mathrm{O}$ interesse pelas plantas de uso medicinal tem crescido consideravelmente nos últimos anos, pois elas têm sido uma fonte valiosa de produtos para manutenção da saúde humana, tornando-se candidatas potenciais para muitas aplicações na indústria farmacêutica. As plantas medicinais são as melhores fontes para se obter uma variedade de drogas. Cerca de $80 \%$ da população mundial usa a medicina tradicional na busca de alívio de alguma sintomatologia dolorosa ou desagradável (Nascimento et al., 2000; Caetano et al., 2002).

Considerando a diversidade de plantas existentes nos diferentes ecossistemas brasileiros, a importância 
reconhecida de algumas no tratamento de doenças, e tendo relatos do agravamento da resistência a antimicrobianos em populações bacterianas, principalmente de origem hospitalar, fica notória a necessidade da busca de novas substâncias com propriedades antimicrobianas para serem utilizadas frente a esses microrganismos (Okeke et al., 1999). Tal fato reforça a crescente investigação do potencial terapêutico de plantas medicinais onde alguns dos seus compostos com propriedade antimicrobiana como flavonoides, alcaloides, triterpenos, sesquiterpenos, taninos, lignanas e saponinas têm sido objetos de interesse para o tratamento de vários tipos de infecções humanas (Verdi et al., 2005). Sendo assim, faz-se necessário a realização de novas investigações de plantas medicinais normalmente empregadas pelas comunidades tradicionais, mas que não tiveram ainda suas potencialidades terapêuticas cientificamente comprovadas, pois a seleção de plantas a partir de informações da medicina tradicional ou popular pode conduzir a descoberta de moléculas promissoras (Hostettmann et al., 2003).

Avicennia schaueriana Stapf \& Leechm. ex Moldenke, Verbenaceae, conhecida popularmente como mangue-preto ou siriúba, é uma espécie endêmica da vegetação de manguezal pertencente à família Verbenaceae. É uma planta arbórea de médio porte com casca lisa castanho-claro, possui folhas esbranquiçadas na face abaxial devido à presença de minúsculas escamas. $\mathrm{O}$ sistema radicular se desenvolve horizontalmente, a poucos centímetros da superfície do sedimento. Das raízes axiais saem ramificações que crescem eretas, expondo-se ao ar e dispostas ao redor do tronco (Schaeffer-Novelli, 1995). As espécies do gênero Avicennia são muito utilizadas pelas comunidades tradicionais para cura de várias doenças (Tabela 1).

Ainda não existem relatos científicos sobre o potencial terapêutico de A. schaueriana. Entretanto, a quantidade de informações sobre as atividades farmacológicas de outras espécies da família Avicenniaceae é de grande importância, tendo em vista as informações originadas pelas comunidades tradicionais, que as utilizam para o tratamento de várias doenças. Neste contexto, o objetivo do trabalho foi avaliar o potencial antibacteriano dos extratos hidro-alcoólicos de folha, raiz e casca de $A$. schaueriana da região de Siribinha, Bahia.

Tabela 1. Principais usos medicinais pelas comunidades tradicionais das espécies do gênero Avicennia.

\begin{tabular}{|c|c|c|}
\hline Espécies & Uso Tradicional & Referências \\
\hline Avicennia africana & $\begin{array}{l}\text { Cura de sarna, parasitas da pele, tumores e } \\
\text { úlceras. }\end{array}$ & Ito et al., 2000; Bandaranayake, 1998. \\
\hline Avicennia alba & $\begin{array}{l}\text { Tratamento de antifertilidade, doenças da } \\
\text { pele, tumores e úlceras. }\end{array}$ & Ito et al., 2000 Bandaranayake, 1998. \\
\hline Avicennia ebracteatus & $\begin{array}{l}\text { Tratamento de queimaduras e mordida de } \\
\text { serpentes. }\end{array}$ & Bandaranayake, 1998. \\
\hline Avicennia germinans & $\begin{array}{l}\text { Tratamento de reumatismo, dor de garganta } \\
\text { e úlceras da boca. }\end{array}$ & Bandaranayake, 1998; Sharma, 1996. \\
\hline Avicennia marina & $\begin{array}{l}\text { Tratamento de reumatismo, úlceras e } \\
\text { pústula. }\end{array}$ & Mahasneh, 2002; Bandaranayake, 1998. \\
\hline Avicennia nítida & Tratamento de tumores e úlceras. & $\begin{array}{l}\text { Bandaranayake, 1998; Madhu \& Madhu, } \\
1997 .\end{array}$ \\
\hline Avicennia officinalis & Diurético, cura para hepatites e leprose. & $\begin{array}{l}\text { Madhu \& Madhu, 1997; Basak et al., } \\
1996 .\end{array}$ \\
\hline Avicennia tomentosa & Tratamento de reumatismo. & $\begin{array}{l}\text { Bandaranayake, 1998; Majumdar \& Patra, } \\
1979 .\end{array}$ \\
\hline
\end{tabular}

\section{MATERIAIS E MÉTODOS}

\section{Material vegetal}

A casca, raiz e folha de Avicennia schaueriana Stapf \& Leechm. ex Moldenke, Verbenaceae, foram coletadas em agosto de 2004 no povoado pesqueiro de Siribinha, localizado no município de Conde, na região litoral norte do Estado da Bahia, Brasil, entre as coordenadas $14^{\circ} 45^{\prime} 23$ " latitude Sul e $037^{\circ} 31^{\prime} 15^{\prime \prime}$ longitude Oeste, de acordo com a metodologia descrita por Campos (1991). A identificação da espécie foi realizada no Instituto
Brasileiro de Geografia e Estatística (IBGE), e a exsicata se encontra depositada no acervo do Herbário Radambrasil (HRB) sob o número de registro 533573.

\section{Preparo dos extratos}

Os extratos hidro-alcoólicos foram preparados através do método de maceração (48 h), utilizando-se a proporção de $1: 3$, sendo $1 \mathrm{~g}$ de cada estrutura vegetal triturada com $3 \mathrm{~mL}$ de etanol (Merck) a 70\% (v/v) (Matos, 1988). Os extratos foram filtrados em papel filtro qualitativo (Quanty, $\mathrm{n}^{\circ} \mathrm{JP} 42$ ) num sistema de vácuo (Marconi, MA 
057/1) e concentrados através do evaporador rotatório (Heidolph, Laborata 4000 ) a $40^{\circ} \mathrm{C}$, sob pressão reduzida, e por liofilização (Labconco, Freezone 4.5) para eliminação total do solvente. Os extratos foram armazenados em frasco âmbar e conservados no dessecador até o preparo das soluções em diferentes concentrações.

\section{Microrganismos}

Seis cepas bacterianas foram usadas nos ensaios de sensibilidade: Staphylococcus aureus ATTC 6835, Micrococcus luteus ATCC 9341, Escherichia coli ATCC 10536, Pseudomonas aeruginosa ATCC 15442, Salmonella cholerea-suis ATCC 10708 e Klebsiella pneumoniae ATCC 700603. As cepas bacterianas têm origem da bacterioteca do Instituto Nacional de Controle de Qualidade em Saúde (INCQS). As cepas bacterianas foram mantidas em tryptic soy agar (TSA) (Merck) a $\pm 4{ }^{\circ} \mathrm{C}$.

\section{Método da difusão em disco}

O ensaio antimicrobiano foi realizado através do método de difusão em disco (Bauer et al., 1966), com base no documento M2-A8 (NCCLS, 2003a), onde cada disco estéril de papel filtro (Qualit, $\mathrm{n}^{\circ}$ 045.PF) de 6,0 mm de diâmetro foi impregnado com alíquotas $(10 \mu \mathrm{L})$ dos extratos de A. schaueriana nas concentrações de 1, 2 e 3 $\mathrm{mg} /$ disco (Santos et al., 2007a). No teste controle negativo foi aplicado $10 \mu \mathrm{L}$ de dimetilsufóxido (DMSO) (Merck), utilizado na ressuspensão dos extratos, e como controle positivo foram usados os antibióticos eritromicina $(15 \mu \mathrm{g} /$ disco) e ciprofloxacin $(5 \mu \mathrm{g} /$ disco) (Sensibiodisc, Cecon). $\mathrm{O}$ inóculo bacteriano foi preparado por suspensão direta em solução salina $(0,9 \%)$, a partir de uma cultura de $24 \mathrm{~h} \mathrm{em}$ TSA. A suspensão foi ajustada através da escala padrão 0,5

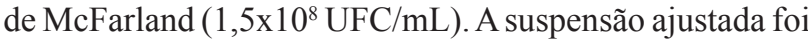
semeada em placa de Petri (90 mm de diâmetro) contendo agar Mueller-Hinton (AMH) (Himedia). Um conjunto predeterminado de discos contendo os extratos vegetais foi colocado na superfície do AMH. As placas foram incubadas na estufa a $37^{\circ} \mathrm{C}$ por $24 \mathrm{~h}$. Após o período de incubação foi realizada a leitura do diâmetro dos halos de inibição de crescimento bacteriano, incluindo o diâmetro do disco.

\section{Concentração Inibitória Mínima (CIM)}

Os ensaios de sensibilidade de microdiluição em caldo foram feitos, seguindo as recomendações da National Committee for Clinical Laboratory Standards (2003b). Os testes foram realizados em caldo MuellerHinton $(\mathrm{CMH})$ (Himedia) contido em microplacas de 96 poços. Os extratos brutos da casca, raiz e folha de $A$. schaueriana foram aplicados nos poços, seguindo a técnica de diluição seriada, nas concentrações de 0,$15 ; 0,31$; 0,$62 ; 1,25 ; 2,50 ; 5,00 ; 10,00 ; 20,00 \mathrm{mg} / \mathrm{mL}$. Foi realizada diluição seriada $(0,50 ; 1,00 ; 2,00 ; 4,00 ; 8,00 ; 16,00 ; 32,00$ $\mu \mathrm{g} / \mathrm{mL}$ ) de cloranfenicol (Henrifarma) como controle positivo e DMSO como controle negativo. A partir de uma suspensão ajustada da escala padrão 0,5 de McFarland das cepas bacterianas testadas, foram feitas diluições com água destilada autoclavada de 1:10 (v/v) para obter uma concentração final de bactérias de $5 \times 10^{4} \mathrm{UFC} /$ poço. As placas foram incubadas a $37{ }^{\circ} \mathrm{C}$ por $24 \mathrm{~h}$. A leitura foi realizada através da mudança de cor do revelador, cloreto de 2,3,5-trifeniltetrazólio (TTC) (Nuclear), considerando o resultado positivo a ausência de coloração e negativo na presença de coloração rosa-avermelhada (Ferreira, 2007; Santos, 2007b).

\section{Analise estatística}

Todos os testes de sensibilidade dos extratos vegetais foram realizados em triplicata e avaliados pelos testes de Kruskal-Wallis e Mann-Whitney, visando comparar as tendências centrais de inibição do crescimento bacteriano entre as estruturas vegetais da espécie em estudo (Callegari-Jacques, 2003). Foi utilizado o programa estatístico GraphPad InsTat (versão 3) para análise dos dados. Os testes foram considerados significantes quando o valor de $p$ foi menor que 0,05 .

\section{RESULTADOS E DISCUSSÕES}

Os resultados obtidos mostram que os extratos hidro-alcoólicos da casca, folha e raiz de Avicennia schaueriana inibiram o crescimento in vitro de Staphylococcus aureus (ATTC 6835), Micrococcus luteus (ATCC 9341) e Klebsiella pneumoniae (ATCC 700603), sendo os extratos das cascas e raízes os que apresentaram uma maior atividade antibacteriana (Tabela 2). Entretanto, nas concentrações testadas, os mesmos não foram capazes de inibir o crescimento das cepas de Escherichia coli (ATCC 10536), Pseudomonas aeruginosa (ATCC 15442) e Salmonella cholerea-suis (ATCC 10708). Embora que outros membros do gênero de Avicennia já tenham apresentado propriedade antimicrobiana para Pseudomonas aeruginosa com extrato metanólico e butanólico de $A$. marina (Bhosale et al., 2002; Mahasneh, 2002) e o extrato metanólico de Avicennia resinifera (Bloor, 1995).

A propriedade antibacteriana dos extratos de Avicennia schaueriana confirma os relatos da literatura, de que os membros da família Verbenaceae possuem grande utilidade na medicina tradicional, sendo esse potencial associado à presença de vários compostos químicos com atividade antimicrobiana, antiinflamatória e citotóxica (Bloor, 1995), tais como triterpenóides em Avicennia tomentosa (Majumdar \& Patra, 1979) e A. alba (Bandaranayake, 2002); taninos e triterpenos (Padmakumar \& Ayyakkannu, 1997), isoverbascoside, deramnosilverbascoside e verbascoside (Fauvel et al., 1993) em A. marina; flavonóides (Basak et al., 1996) e 
saponinas em A. officinalis (Champagne et al., 1992).

De acordo com as concentrações dos extratos e com as cepas analisadas houve formação de halos de inibição do crescimento que variam de 7,67 a $18,0 \mathrm{~mm}$ (Tabela 2). Não houve diferença significativa $(p>0,05)$ dos diâmetros dos halos de inibição de crescimento das cepas de $S$. aureus, $M$. luteus e K. pneumoniae quando utilizado extrato da casca nas concentrações de 2 e $3 \mathrm{mg} /$ disco. O extrato hidro-alcoólico da folha de A. schaueriana inibiu o crescimento Klebsiella pneumoniae ATCC 700603 na concentração de $3 \mathrm{mg} / \mathrm{disco}$, podendo tornar-se essa ação antibacteriana de grande importância devido ao seu caráter seletivo. O extrato da raiz apresentou maior atividade antibacteriana do que os outros extratos frente às bactérias da família Micrococcaceae, formando os maiores halos de inibição (>17 mm) de crescimento bacteriano.

Tabela 2. Media e desvio padrão dos halos de inibição $(\mathrm{mm})$ obtidos pelo método de difusão em disco, utilizado na análise do extrato hidro-alcoólico de A. schaueriana (folha, raiz e casca). Refazer esta tabela, usando os recursos do processador, sem negrito, sem divisão entre as linhas e com linhas de tamanho $1 / 2 \mathrm{pt}$.

\begin{tabular}{|c|c|c|c|c|c|c|c|}
\hline \multirow{3}{*}{ Microrganismos } & \multirow{3}{*}{$\begin{array}{l}\text { Concentrações } \\
(\mathrm{mg} / \mathrm{disco})\end{array}$} & \multicolumn{6}{|c|}{ Diâmetro do Halo de Inibição (mm)* } \\
\hline & & \multicolumn{2}{|c|}{ Casca } & \multicolumn{2}{|c|}{ Folha } & \multicolumn{2}{|c|}{ Raiz } \\
\hline & & MA & $D P$ & MA & $D P$ & MA & $D P$ \\
\hline \multirow{3}{*}{$\begin{array}{c}\text { Staphylococcus aureus } \\
\text { ATTC } 6835\end{array}$} & 1 & - & - & - & - & 9,00 & 0,00 \\
\hline & 2 & 9,67 & 0,58 & - & - & 10,33 & 0,58 \\
\hline & 3 & 9,67 & 0,58 & - & - & 11,67 & 0,58 \\
\hline \multirow{3}{*}{$\begin{array}{l}\text { Micrococcus luteus } \\
\text { ATCC } 9341\end{array}$} & 1 & 10,00 & 0,00 & - & - & 16,00 & 0,00 \\
\hline & 2 & 11,67 & 0,58 & - & - & 18,00 & 0,00 \\
\hline & 3 & 7,67 & 0,58 & - & - & 17,33 & 1,15 \\
\hline \multirow{3}{*}{$\begin{array}{l}\text { Klebsiella pneumoniae } \\
\text { ATCC } 700603\end{array}$} & 1 & - & - & - & - & - & - \\
\hline & 2 & - & - & - & - & - & - \\
\hline & 3 & 9,00 & 1,00 & 7,66 & 0,58 & 7,67 & 0,58 \\
\hline
\end{tabular}

* Halos de inibição incluindo o diâmetro do disco (6 mm); Ausência de inibição; MA média aritmética do diâmetro do halo de inibição bacteriana; $D P$ desvio padrão do diâmetro do halo de inibição bacteriana.

Quando comparadas as partes vegetais de $A$. schaueriana fica evidente a diferença de sensibilidade das cepas bacterianas estudadas frente aos extratos da casca e raiz em relação ao extrato da folha (Tabela 2). Tal fato pode estar relacionado à distribuição de metabólitos secundários com propriedades antibacterianas presentes em maior concentração na casca e na raiz ou pelo fato da folha não apresentar constituintes químicos com potencial antimicrobiano para inibir o crescimento de bactérias Grampositivas, tendo em vista que o extrato da folha apresentou ação inibitória seletiva apenas para uma bactéria Gramnegativa. $\mathrm{O}$ extrato da raiz nas concentrações de 2 e $3 \mathrm{mg} /$ disco não apresentou diferença significativa $(p=0,10)$ das médias do diâmetro dos halos de inibição do crescimento de $S$. aureus e $M$. luteus, mas foi considerado significativo $(p<0,05)$ quando comparado com as médias do diâmetro dos halos de inibição do crescimento de $S$. aureus, $M$. luteus e K. pneumoniae. Isso pode estar relacionado à menor atividade antimicrobiana do extrato da raiz para cepa de K. pneumoniae.

Oensaiocomeritromicina $(15 \mu \mathrm{g} / \mathrm{disco})$ apresentou formação de halos de inibição do crescimento entre $12 \mathrm{e}$ $26 \mathrm{~mm}$ para as cepas de $S$. aureus, M. luteus e E. coli e com ciprofloxacin $(5 \mu \mathrm{g} / \mathrm{disco})$ formou halos de inibição do crescimento entre 26 e $38 \mathrm{~mm}$ para $P$. aeruginosa, $S$. cholerea-suis e K. pneumoniae. Estes resultados estão de acordo às recomendações sugeridas pelo CLSI (2005). Os experimentos com discos embebidos com DMSO não apresentaram formação de halo de inibição do crescimento bacteriano, confirmando os relatos da literatura.

O extrato da casca na concentração de $3 \mathrm{mg} /$ disco apresentou formação do halo de inibição do crescimento para $M$. luteus inferior $(8 \mathrm{~mm})$ às concentrações de $1 \mathrm{e}$ $2 \mathrm{mg} / \mathrm{disco}$, fato que pode estar relacionado ao processo de antagonismo, onde o componente com propriedade antimicrobiana pode ter se agregado a um elemento químico do extrato, reduzindo a ação antimicrobiana da molécula.

Os resultados da concentração inibitória mínima (CIM) com os extratos hidro-alcoólicos de Avicennia schaueriana apresentaram excelente reprodutibilidade, sendo a média do valor da CIM do extrato da casca de 2,5 $\mathrm{mg} / \mathrm{mL}$ para $S$. aureus e de $5 \mathrm{mg} / \mathrm{mL}$ para $K$. pneumoniae e M. luteus e o extrato da folha obteve o maior valor de $\mathrm{CIM}$, de $10 \mathrm{mg} / \mathrm{mL}$ para K. pneumoniae. Entretanto, o extrato hidro-alcoólico da raiz se mostrou mais eficiente, apresentando concentrações inibitórias mínimas de $5 \mathrm{mg} /$ $\mathrm{mL}$ para $K$. pneumoniae e de $0,62 \mathrm{mg} / \mathrm{mL}$ para $S$. aureus e $M$. luteus. O resultado do cloranfenicol foi de $2 \mu \mathrm{g} \mathrm{mL}$ para $K$. pneumoniae, de $4 \mu \mathrm{g} / \mathrm{mL}$ para $M$. luteus e de 8 $\mu \mathrm{g} / \mathrm{mL}$ para $S$. aureus. A CIM do extrato da raiz de $A$. schaueriana foi considerada significativa $(p=0,01)$ pelo teste Kruskal-Wallis, quando comparado às médias das concentrações dos extratos frente às cepas de $S$. aureus, $M$. luteus e K. pneumoniae. Estes resultados confirmam a diferença de sensibilidade dos microrganismos 
estudados em relação aos extratos da raiz e casca. Os extratos de A. schaueriana apresentaram promissoras concentrações inibitórias mínimas (CIM), tendo em vista que etapas posteriores de purificação e identificação do(s) componente(s) bioativo(s) poderá(ão) reduzir ainda mais a CIM e potencializar a sua atividade antibacteriana. Os resultados dos testes estatísticos confirmam a diferença de sensibilidade dos microrganismos estudados frente aos extratos de A. schaueriana.

Os resultados corroboram com os dados etnobotânicos disponíveis na literatura sobre o uso medicamentoso dos membros da família Verbenaceae. Entre os princípios ativos de plantas com potencial antimicrobiano, os flavonoides são um dos constituintes químicos encontrados na literatura cientifica para o gênero Avicennia. Tal fato pode colaborar no entendimento dos resultados obtidos com os extratos da casca, folha e raiz de A. schaueriana de inibirem o crescimento de $S$. aureus, $M$. luteus e $K$. pneumoniae, pois a habilidade desse grupo fenólico de se complexar com a parede de células bacterianas, pode resultar no rompimento das membranas microbianas (Cowan, 1999).

\section{CONCLUSÃO}

De acordo com os resultados obtidos foi demonstrado o potencial antibacteriano dos extratos hidro-alcoólicos da casca, folha e raiz de Avicennia schaueriana. Os extratos da raiz e casca de A. schaueriana mostraram uma maior atividade antibacteriana frente às bactérias Gram-positivas. O extrato da folha mostrou uma atividade seletiva de inibição do crescimento da cepa de $K$. pneumoniae. $\mathrm{O}$ extrato da raiz mostrou-se mais eficiente do que os extratos da casca e folha, tanto na formação dos maiores halos de inibição do crescimento das cepas bacterianas como nas menores concentrações inibitórias mínimas frente às bactérias estudadas, tornando-se alvo para futuras pesquisas. Este estudo representou uma descoberta inédita do potencial antibacteriano dos extratos hidroalcoólicos da casca, folha e raiz de Avicennia schaueriana, confirmando os relatos da família Avicenniaceae como uma interessante fonte de constituintes antibacterianos, além de ratificar a importância das informações etnofarmacológicas de muitas comunidades tradicionais para seleção de plantas com propriedades biológicas.

\section{AGRADECIMENTOS}

Ao Biólogo E. P. Queiroz do Instituto Brasileiro de Geografia e Estatística (IBGE) pela identificação taxonômica da espécie. Ao Laboratório de Estudos em Meio Ambiente da Universidade Católica do Salvador e ao Laboratório de Pesquisa em Microbiologia Clínica da Universidade Federal da Bahia.

\section{REFERÊNCIAS}

Bandaranayake WM 1998. Traditional and medicinal uses of mangroves. Mangroves and Salt Marshes 2: 133-148.

Bandaranayake WM 2002. Bioactivities, bioactive compounds and chemical constituents of mangrove plants. Wetlands Ecol Management 10: 421-452.

Basak UC, Das AB, Das P 1996. Chlorophyll, carotenoids, proteins and secondary metabolites in leaves of 14 species of mangroves. Bul Mar Sci 58: 654-659.

Bauer AW, Kirby WM, Sherris JC, Turck M 1966. Antibiotic susceptibility testing by standardized single disk method. Amer J Clin Pathol 45: 493-496.

Bhosale SH, Nagle VL, Jagtap TG 2002. Antifouling potential of some marine organisms from India against species of Bacillus and Pseudomonas. Mar Biotechnol 4: 111-118.

Bloor SJ 1995. A survey of extracts of New Zealand indigenous plants for selected biological activities. New Zeal J Bot 33: 523-540.

Caetano N, Saraiva A, Pereira R, Carvalho D, Pimentel MCB, Maia MBS 2002. Determinação de atividades antimicrobiana de extratos de plantas de uso popular como antiflamatório. Rev Bras Farmacogn 12: 132-135.

Callegari-Jacques SM 2003. Bioestatística: princípios e aplicações. Porto Alegre: Artmed.

Campos JM 1991. Guia prático de terapêutica externa: métodos e procedimentos terapêuticos de grande simplicidade e eficácia. São Paulo: Cultrix/Pensamento.

Champagne DE, Koul O, Isman MB, Scudder GGE, Towers GHN 1992. Biological activity of limonoids from the rutales. Phytochemistry 31: 377-394.

Clinical and Laboratory Standards Institute 2005. Performance standards for antimicrobial susceptibility testing; fifteenth informational supplement. CLSI/NCCLS document M100-S15 [ISBN 1-56238-556-9], Wayne, Pennsylvania.

Cowan MM 1999. Plant products as antimicrobial agents. Clin Microbiol Rev 12: 564-582.

Fauvel MT, Taoubi K, Gleye J, Fouraste I 1993. Phenylpropanoid glycosides from Avicennia marina. Phytochem Notes 95: 387.

Ferreira FS 2007. Investigação do poder antibiótico in vitro de extratos brutos de raiz, casca e folha de Rhizophora mangle L. Salvador, 46p. Monografia de Especialização em Microbiologia - Faculdade de Farmácia, Universidade Federal da Bahia.

Hostettmann K, Queiroz EF, Vieira PC 2003. Princípios Ativos de Plantas Superiores. São Paulo: EDUFSCAR.

Ito C, Katsuno S, Kondo Y, Tan HT, Furukawa H 2000. Chemical constituents of Avicennia alba: isolation and structural elucidation of new naphthoquinones and their analogues. Chem Pharm Bull 48: 339-343.

Matos FJA 1988. Introdução a Fitoquímica Experimental. Fortaleza: EUFC.

Madhu K, Madhu R 1997. Biotoxicity of mangroves on fingerlings of Liza macrolepis (Smith). J Andaman Sci 
Assoc 13: 59-65.

Mahasneh AM 2002. Screening of some indigenus Qatari medicinal plants for antimicrobial activity. Phytotherapy Res 16: 751-753.

Majumdar SG, Patra G 1979. Chemical investigation of some mangrove species: part I genus Avicennia. J Indian Chem Soc 56: 111-113.

Nascimento GGF, Locatelli J, Freitas PC, Silva GL 2000. Antibacterial activity of plant and phytochemicals on antibiotic-resistant bacteria. Braz J Microbiol 31: 247256.

National Committee for Clinical Laboratory Standards (NCCLS) 2003a. Performance standards for antimicrobial disk susceptibility tests: approved standard. 8.ed. NCCLS document M2-A8 (ISBN 1-56238-485-6), Wayne, Pennsylvania.

National Committee for Clinical Laboratory Standards (NCCLS) 2003b. Methods for dilution antimicrobial susceptibility tests for bacteria that grow aerobically: approved standard. 6.ed. NCCLS document M7-A6 (ISBN 1-56238-486-4), Wayne, Pennsylvania.

Okeke IN, Lamikanra A, Edelman R 1999. Socioeconomic and behavioral factors leading to acquired bacterial resistance to antibiotics in developing countries. Emerg Infect Dis 5: 18-27.

Padmakumar K, Ayyakkannu K 1997. Antiviral activity of marine plants. Indian J Vir 13: 33-36.

Santos SC 2007a. Prospecção do potencial antibacteriano de Avicennia schaueriana (Stapf \& Leechman). Salvador, 43p. Monografia de Especialização em Microbiologia Faculdade de Farmácia, Universidade Federal da Bahia.

Santos SC, Ferreira FS, Rossi-Alva JC, Fernandez LG 2007b. Atividade antimicrobiana in vitro do extrato de Abarema cochliocarpos (Gomes) Barneby \& Grimes. Rev Bras Farmacogn 17: 215-219.

Schaeffer-Novelli Y 1995. Manguezal: ecossistema entre a terra e o mar. São Paulo: Universidade Federal da Bahia.

Sharma G 1996. Iridoid glycosides from Avicennia officinalis. Indian J Chem 35: 459-462.

Verdi LG, Brighente IMC, Pizzolatti MG 2005. Gênero Baccharis (Asteraceae): aspectos químicos, econômicos e biológicos. Quim Nova 28: 85-94. 